University of Wollongong

Research Online

Faculty of Social Sciences - Papers (Archive) Faculty of Arts, Social Sciences \& Humanities

2015

Why do people access news with mobile devices? Exploring the role of suitability perception and motives on mobile news use

Hongjin Shim

Korea Information Society Development Institute

Kyung Han You

Pennsylvania State University

Jeong Kyu Lee

University of Wollongong, jklee@uow.edu.au

Eun Go

Pennsylvania State University

Follow this and additional works at: https://ro.uow.edu.au/sspapers

Part of the Education Commons, and the Social and Behavioral Sciences Commons

Research Online is the open access institutional repository for the University of Wollongong. For further information contact the UOW Library: research-pubs@uow.edu.au 


\title{
Why do people access news with mobile devices? Exploring the role of suitability perception and motives on mobile news use
}

\author{
Abstract \\ Using self-reported survey data $(\mathrm{N}=281)$, the present study explores the structural relationships among \\ mobile users' perceptions of the suitability of two types of mobile news (political feature news and \\ entertainment news), users' motivations for mobile news usage, and their behavioral patterns. Our \\ findings show that two types of perceived suitability for mobile news, particularly for political feature \\ news, are strongly associated with all dimensions of motivations for mobile news usage. Furthermore, as \\ predicted, our findings show that the information-seeking motive is the very factor that determines mobile \\ news usage. The results also reveal that the accessibility motive mediates the relationship between the \\ perceived suitability of obtaining news via a mobile device and users' mobile news behavior. However, \\ contrary to our expectation, the social utility motive does not mediate the relationship between users' \\ perceptions of the suitability of mobile devices for this purpose and their mobile news usage. Finally, the \\ information-seeking and accessibility motives each have an indirect effect on the association between \\ perceived suitability and mobile news usage. The implications of the study and recommendations for \\ future research are also discussed.
}

\section{Keywords}

why, mobile, news, devices, exploring, role, suitability, perception, motives, access, people, do

\section{Disciplines}

Education | Social and Behavioral Sciences

\section{Publication Details}

Shim, H., You, K., Lee, J. \& Go, E. (2015). Why do people access news with mobile devices? Exploring the role of suitability perception and motives on mobile news use. Telematics and Informatics, 32 (1), 108-117. 
Why Do People Access News with Mobile Devices?

\title{
Exploring the Role of Suitability Perception and Motives on Mobile News Use
}

\author{
Hongjin Shim a, Kyung Han You b, Jeong Kyu Lee c, Eun Go b,* \\ a Convergence and Future Research Division, Korea Information Society Development Institute, 36 Jang gun maeul, \\ 3 gil, Gwacheon-si, Gyeonggi-do 427-710, Republic of Korea \\ b College of Communications, The Pennsylvania State University, 115 Carnegie Building, University Park, PA 16802, \\ United States \\ c The Center for Health Initiatives, Innovation Campus, ITAMS Building 233, University of Wollongong, 12 Northfields \\ Avenue, NSW 2522, Australia
}

*Corresponding author. Tel.: +13526822355 .

E-mail addresses: hjshim@kisdi.re.kr (H. Shim), kyunghanyou@gmail.com (K.H. You), lee.jeongkyu@gmail.com (J.K. Lee), eungo83@gmail.com (E. Go).

\begin{abstract}
Using self-reported survey data $(N=281)$, the present study explores the structural relationships among mobile users' perceptions of the suitability of two types of mobile news, i.e., political feature news and entertainment news, motivations for mobile news usage, and their behavioral patterns. Our findings show that two types of perceived suitability for mobile news, particularly for political feature news, are strongly associated with all dimensions of motivations for mobile news use. Further, as we predicted, our findings showed that the information-seeking motive was the very factor that determines mobile news usage. The results also presented that the accessibility motive mediated the relationship between the perceived suitability of obtaining news via a mobile device and users' mobile news behavior. However, contrary to our expectation, the social utility motive does not mediate the relation between the users' perceptions of the suitability of mobile devices for this purpose and their mobile news usage. Finally, the
\end{abstract}


information-seeking and accessibility motives each have an indirect effect on the association between perceived suitability and mobile news use behavior. The implications of the study and recommendations for future research directions are also discussed.

Keywords: Smart phone, Mobile news, Social networking service, Motivations, Perceived suitability, Structural Equation Modeling

\section{Introduction}

News content is among the most popular mobile content, because it is easy to circulate on the mobile device and the smartphone interface greatly simplifies the process of accessing news. With new functionality in the current mobile environment, the $3 \mathrm{G}$-enabled mobile device has expanded beyond a person-to-person conversational device to a media-rich platform for delivering news (Wei, 2008). In fact, the number of mobile news apps download has been increased in many countries, including South Korea, even though newspaper reading has significantly decreased since the new millennium (Westlund \& Bohlin, 2008). Moreover, a recent report from the Pew Research Center (2012) also supports the phenomenon, showing that over half of smartphone users accessed news with their mobile phone.

Furthermore, as mobile news-delivery services have become diversified, users can select online news channels on mobile devices based on their specific preferences. For example, mobile users are able to easily access news content anywhere anytime by visiting mobile news websites (mobile news apps) and/or logging into social media services such as Twitter, Facebook, MySpace, and Metoday (Falaki et al., 2010). In fact, social networking services comprise a large 
segment of online news services in which users share, bookmark, and reproduce news content.

Given the aforementioned news sources on mobile devices, how people use such sources can be influenced by diverse psychological factors. First, a number of previous studies have argued that news consumption behaviors are dictated by motivations for consuming news on mobile devices. In particular, uses and gratifications theory (U\&G) explains such a relationship by arguing that individuals' media usage behaviors are guided by specific needs and motivations (Rubin, 2002, 2009). In addition to motivation, the present study postulates that the perception of mobile device suitability to accessing news can also influence people's mobile news consuming behaviors by driving certain motivations. In other words, if people perceive a mobile device as a good tool for accessing certain types of news, then they are more likely to use it for that perceived purpose, which in turn leads to specific usage patterns.

Thus, the present study aims to determine (1) how users' perceptions of the suitability of mobile devices for obtaining mobile news drives mobile users' motives, and (2) the particular types of motivations associated with mobile-based consumption of different kinds of news. More specifically, this study considers two kinds of news-entertainment news and political feature news - and identifies the extent to which users perceive mobile devices as suitable for accessing them. Furthermore, the study intends to investigate how three types of motivation-information utility, social utility, and accessibility-influence mobile news consumption behaviors via mobile news apps and mobile social-networking services.

\section{Literature Review}

\subsection{Changes in News Consumption Behaviors with Smartphones}


The arrival of smartphones has changed the way in which people consume news media. Presently, it appears that many people, particularly, those aged 18 to 34 who comprise the majority of smartphone users, are more likely to use smartphones to get their news than any other source (Pew Research Center, 2012). The rapid growth of mobile phones as a source of news has also changed the landscape of news media content, as the news content of mobile devices (e.g., in mobile news apps) predominantly consist of soft news, particularly entertainment news (Kim, 2011).

The proliferation of smartphones has given rise to a new format of news article-short, simple and light-in accordance with the features of the mobile interface (Korea Press Foundation, 2012). The mobile interface offers a unique set of features-including small screen size, ubiquitous information access, and touch screen- all which have caused different behavioral patterns associated with information news access and consumption. For instance, users might prefer to read short articles on mobile devices due to the small screen size and limited data storage, and to avoid long loading times. Therefore, in accordance with these limitations of mobile phones, news organizations might tend to reorganize news content in order to optimize it for a mobile phone interface by making it vivid, short and light. For this reasons, news articles in mobile news apps tend to focus on celebrity or sports news, which are characterized as vivid, short and light rather than news about politics or current events. Given the abundance of soft news in mobile news apps or mobile news website, it can be speculated that people's news consuming behavior would differ from traditional news consuming behaviors. For example, they might have different perceptions about the suitability of news content type on mobile phones. In other words, as news organizations produce and place entertainment oriented content on mobile 
news websites, users might become more likely to perceive mobile devices as suitable for consuming soft news.

Furthermore, due to the accessibility of mobile devices, social networking sites (SNSs) have become primary news sources. Social networking sites provide new opportunities for userfor example, users can choose news articles that they want to post on their social networking sites- thereby increasing their sense of agency. At the same time, SNS users are also more likely to be exposed to a series of random selected news articles by others. Thus, in SNSs, users are exposed to multiple layers of source (e.g., the person who posted the article, medium itself-e.g., Facebook, and the original news source-news organization) which might cause loss of authoritative voices of news organizations. More importantly, it is assumed that news consumption via SNSs can also be guided by more diversified motivations such as accessibility or information seeking, not just by social utility which has been found as a primary motivation for using SNSs.

As such, an increase in the use of mobile devices as a news source has changed people's news consumption behaviors in that it offers a wide range of possibilities. Therefore, at this point, it is necessary to understand how mobile devices influence our perceptions and the manner in which we consume news. Taken all together, this study is geared toward revealing the factors that drive the changes in news consumption behaviors on mobile devices.

\subsection{Perceived Suitability for Accessing Mobile News}

A number of psychologists have investigated the relationships among perceptions, motivations, and behavioral patterns by arguing that the individual's perception (or recognition) of his/her desires or needs drive the motivation to obtain gratification, then, the motivation 
stimulates an individual's behavior (Steers \& Porter, 1991; Wicklund \& Gollwitzer, 1982). A large body of research has attempted to investigate such relationships. For example, (extended) technology acceptance model (TAM) studies have been conducted to analyze the relations between behavior and perceptions associated with the motivations of information technology users by investigating how perceptions associated with motivations influences behavior across the many information technologies and contexts (King \& He, 2006). Research on consumer behaviors is another important stream of studies that explores these relationships, shedding light on the cognitive aspects of decision making in regard to consumers' decision processes and choice behaviors (Hirschman \& Holbrook, 1982; Holbrook, 1994). In particular, scholars found that consuming behavior is motivated by recognition or judgment on utilitarian value of the products they purchase. For example, Sheth and colleagues (1991) developed a perceived-value framework relating to the perceived utility of a specific choice, based on which they suggested that functional value is a key predictor of consuming behavior.

Perceived value, defined as 'individuals' perceived preferences for and overall assessment of the utility of media content (or product) on the basis of perceptions of what is received and what is given," (Zeithaml, 1988, p.14) is relevant to the perceptions of suitability because it is, by recognizing a certain thing's utility, that people are able to judge its suitability. In the context of mobile phone use for news consumption, if people think a mobile phone has utilitarian values for consuming news, then, they turn to confirm that the mobile phone is suitable for accessing news. If this is the case, as the previous literature states, such perception (i.e., the perceived suitability of using mobile devices to access news) can drive individuals' motivation to use mobile devices, which in turn leads them to mobile use behaviors. 
More specifically, in the study, we explore how people evaluate the suitability of mobile devices for accessing two types of news because it is assumed that users' perceptions of the suitability of mobile devices for accessing different types of news leads to different motivations for using mobile devices. Types of news can be broadly divided into two categories - soft news and hard news. Hard news is defined as "any story that focuses on issues of ongoing policy consideration, factual accounting of current public events, or social issues and controversies that concern members of the audience" whereas soft news is referred to as "any story that focuses on a human interest topic, feature or non-policy issue" (Scott \& Gobets, 1992, p.408). Political news and entertainment news are the most primary examples of hard news and soft news, respectively. Therefore, this study takes these two types of news into account for investigating the association with motivations for using online news.

Hard news is likely to be up-to-the-minute news, thus, it usually aims for providing important or immediate information in a timely manner. On the other hand, soft news tends to be for entertaining people, given that this type of news deals with human-interest stories. Therefore, people who perceive mobile devices as suitable for accessing hard news (i.e., political news) most likely have information-seeking and accessibility motivations, while those who think mobile devices are suitable for accessing soft news (i.e., entertainment news) are more likely driven by enjoyment or socialization motivations. Therefore, the present study intends to explore the role of perceptions of the suitability of mobile devices for accessing different types of news for driving different motivation for using mobile devices. Thus, the following hypothesis is suggested: 
H1: Users' perceptions of the suitability of accessing two type of news (i.e. political and entertainment news) on a mobile device are associated with different motivations for using mobile news.

\subsection{Motives for Mobile news Use: Three Dimensions}

In light of the growing popularity of mobile devices, scholars have explored how people use mobile devices and why they use them in certain ways. Scholars particularly have shed light on motivational factors to explain people's mobile usage behaviors. The U\&G approach offers a useful framework for considering the motivations that lead users to use their mobile devices in specific ways (e.g., Leung \& Wei, 2000). Based on the premise that the media satisfies the audience's diverse needs (Blumler, 1979; Swanson, 1987), U\&G scholarship has demonstrated that news motives are expected to lead to various modes of behaviors related to news consumption (e.g., Levy \& Windahl, 1984; Palmgreen, Wenner, \& Rayburn, 1980).

While U\&G framework has been applied to diverse type of media, such as television, radio, and the Internet, to explain what drives people to use them, it has identified common motivations, which are social and/or interpersonal utility, leisure (sometimes labeled as passing time or entertainment), information seeking, and convenience (e.g., Conway \& Rubin, 1991; Medelsohn, 1964; Ferguson \& Perse, 2000; Ko, Cho, \& Roberts, 2005; Papacharissi \& Rubin, 2000). In the context of online news consumption, studies have also found a similar set of motivations for consuming online news. For example, Flavián and Guerra (2006) identified five motivations: updating issues, specific information seeking, searching for updated news, leisureentertainment, and habitual use. Similarly, You and colleagues (2013) proposed three dimensions of motivations, i.e., information seeking, social utility, and entertainment, whereas Kang and 
colleagues (2013) generated learning, entertainment, and one-upmanship. Drawing on these studies, the present study could find two common motivations: information seeking and social utility (or socialization), however, an entertainment motive (or passing time motive) was not identified as an independent dimension of motivation, because it was found to be compounded with social utility motive.

In addition to these two motivations, this study also considers a unique dimension of motives relevant to mobile news usage - accessibility motive, because mobile technology is distinct from other communication technologies in that it affords a constant connection to the Internet. Previous studies have considered the accessibility motive to be one of the crucial factors influencing users' choice of information sources (e.g., Borgatti \& Cross, 2003; Yuan et al., 2010), which is similar to the convenience motive, the predictor for using new media services (Papacharissi \& Rubin, 2000).

In sum, based on the literature and on the exploratory factor analysis conducted for this study, three motivations (i.e., information seeking, social utility, and accessibility) were taken into consideration. In the context of mobile news consumption, the information-seeking motive refers to using mobile news to seek specific information, similar to the learning motive. The social utility motive refers to using mobile devices to enhance individuals' social connectedness. In addition, the accessibility motive, referred to as using mobile devices to access news anytime and anywhere, is included in this research as a final factor. Then, it is postulated that these three motivations can explain why people consume mobile news.

\subsection{Mobile News Behavior: Mobile News Apps and Mobile Social Networking}


Unlike other media, mobile news spurs users to engage in diversified modes of news consumption. Unique features of mobile devices, including mobility, hyperlinks, and downloading, enable mobile users to quickly access and dispense with diverse content (Kiousis \& Dimitrova, 2006). In particular, the rapid diffusion of mobile devices is driving the changes currently taking place in information seekers' behavioral patterns relating to news usage. Mobile devices, particularly smart phones, enable information seekers to install and use applications according to their own needs and interest in the news (Verkasalo et al., 2010), such that news audiences no longer rely heavily on the traditional news media such as newspapers and TV, or even the Internet for information. Rather, current news audiences use multiple channels provided by multiple media, and they frequently consume news content by accessing information-sharing services.

As mobile devices provide a number of news applications and websites (Falaki et al., 2010), the concept of news content is undergoing a dramatic change. Regarding the changing environments in which news content is being delivered, the present study first focuses on mobile news consumption via diverse apps or websites in the broad context of news consumption through media such as newspapers, television, and the Internet. Specifically, the study seeks to measure the concentration ratio of such mobile news consumption divided by total news consumption, with the central purpose of clarifying mobile users' behavioral patterns relating to overall news consumption. In addition to mobile apps or news websites, the present study also considers social networking sites as another important source for accessing news. According to a recent survey (Pew research center, 2012), for those who access news on mobile phones, it is found that the use of social networking sites is one of the popular ways to get news. Given that social-networking sites such as Facebook, Me2day, and Twitter are gaining popularity as news 
sources, social-networking services (SNSs) are expected to account for the larger portion of news users and their related activities.

Considering these two different news sources, people's use of specific news sources can be guided by their specific motivations. For example, people who have social utility motivation for accessing mobile news are more likely to consume news via SNS on mobile phones, while those who have information-seeking motivation are prone to access news via mobile news applications that allow users to seek and access a wide variety of information freely based on their preferences. In addition, people with accessibility motivations tend to use both mobile news apps and SNSs, given that their highest priority is convenience or accessibility, regardless of whether their news comes from mobile apps or SNSs. Therefore, by analyzing users' mobile news consuming behaviors through distinguishing between the use of social network sites via mobile devices from other mobile news apps for accessing news, the current study seeks to understand how SNS news consumption differs from other mobile news consumption in terms of specific dimensions of motivation. Thus, the following hypothesis is suggested:

H2: Two types of mobile news consumption behaviors (i.e., mobile news use and social news use) will differ as a function of different motivations (i.e., information seeking, social utility, and accessibility).

\section{Method}

\subsection{Participants}

Data was collected using self-reported survey with 281 participants who consume mobile news via smart phones. Of those included in the analysis, $51.2 \%$ were male and $48.8 \%$ were female. In regard to age, $15.3 \%$ were teenagers, $20.3 \%$ were in their 20 s, $24.1 \%$ were in 
their $30 \mathrm{~s}, 22.0 \%$ were in their $40 \mathrm{~s}$, and $18.1 \%$ were 50 or older. On average, the participants spent 26.6 minutes (ranging from 2 up to 150 minutes) per day on smart phone news use. In addition, the 125 participants who used social media news (SMN) via smart phones did so for an average of 15.4 minutes (ranging from 1 up to 60 minutes) per day.

\subsection{Measures}

\subsubsection{Perceived suitability of mobile news}

The perceived suitability of mobile news was assessed based on eleven statements using a Likert-type scale (ranging from $1=$ Not at all to $5=$ Extremely). These items asked participants to indicate the extent to which they considered using a smart phone to be suitable for getting each type of news were loaded on each factor. Two factors were grouped by an exploratory factor analysis (EFA): perceived suitability for entertainment news and perceived suitability for political feature news.

We measured the perceived suitability of using the smart phone for political feature news on the basis of three items (Im et al., 2008): "It is suitable to consume feature news via smart phone," "It is suitable to consume professional opinions via smart phone," and "It is suitable to consume political feature news via smart phone" (Cronbach's $\alpha=.73$ ). Also, two items were loaded on perceived suitability for entertainment news: "It is suitable to consume entertainment news via smart phone" and "It is suitable to consume gossip news via smart phone" $(r=.48)$.

\subsubsection{Motivations for mobile news usage}

To identify this variable, 13 survey items using a Likert-type scale (ranging from $1=$ Not at all to $5=$ Extremely) were adopted from previous studies focusing on the consumption and 
sharing motivation of news (e.g., Im et al., 2008; Kang et al., 2013). Through the exploratory factor analysis, three factors relating to mobile news motivations were identified: information seeking, social utility, and accessibility.

The first factor, information seeking, was measured with four statements: "To get more correct and professional news," "To get various types of news," "To get in-depth and further information," and "To obtain up-to-date information," each of which refers to the motives to obtain professional and detailed information and knowledge with smart phones. In keeping with previous studies (e.g., You et al., 2013), this factor was named as "information-seeking" (Cronbach's $\alpha=.81$ ).

The following items were loaded on the second factor: "To let others know up-to-date information," "Not to become old-fashioned," "To chat with others immediately," "To continue to follow up a specific event," and "Because it is more interesting than news on other medium." "Because it is easy to express my opinion" referred to the satisfaction of being social by sharing news and information via smart phone, and thus this factor was designated as "social utility" (Cronbach's $\alpha=.70)$.

The third factor was measured with two items, "Because it is convenient to find news I want" and "To easily access information at any place," which referred to the motivation to satisfy accessibility by accessing information at any time and place. This factor was, therefore, called "accessibility" $(r=.58)$.

\subsubsection{Consumption of mobile news}

Mobile news consumption comprises two factors: the degree of concentration of mobile news use and the degree of social networking news use via smart phones. The first factor, the 
degree of concentration of mobile news (CRMN) use, was included in order to understand users' media-use behavioral patterns related to news media usage as a whole. The self-reported items were used to measure the duration of users' news media consumption, including through TV news, newspapers, the Internet, and smart phones. The concentration ratio of mobile news use was then computed by taking the duration of the mobile news use and dividing it by total time of news use.

$$
C R_{m n}=\text { Smart phone news use } \div \text { Total news use (TV, Newspapers, Internet, and Smart Phones) }
$$

Further, to investigate the degree of social networking news use as an alternative news platform, the item measuring the time of social media news use via mobile device was added as a second dimension.

\subsection{Data Analysis Plan}

A structural equation modeling (SEM) analysis was performed in order to test the hypothesized model using Mplus 6.1 (Muthen \& Muthen, 2007). The analysis was conducted in two ways in order to cross-check the results. First, the model parameters were estimated using the Maximum Likelihood (ML) estimation method. However, the ML estimators may have been influenced by non-normal distributional characteristics (i.e., skewness and kurtosis) found for some of the variables (Boomsma, 2000; Boomsma \& Hoogland, 2001; Muthen \& Muthen, 2007). The bootstrap method is known to be an effective way of offsetting statistical problems associated with non-normal distributions, as it does not rely on any a priori assumptions regarding sampling distributions (including multivariate normality) (Efron \& Tibshirani, 1993). 
In addition, this non-parametric technique is superior to conventional methods (e.g., Baron \& Kenny, 1986) for estimating and testing hypotheses concerning mediation (MacKinnon, Fairchild, \& Fritz, 2007; Preacher \& Hayes, 2004; Preacher \& Hayes, 2008). As a result, this study tested the statistical significance of the parameters not only with traditional parametric tests using ML estimation but also with the bootstrap method. All the parameters in the hypothesized model were estimated 5,000 times by repeatedly sampling cases with replacements from the data and estimating the model in each resample (5,000 bootstrap sample draws).

In order to test the hypotheses about the direct as well as the indirect effects of perceptions on smart phone news use, we developed a structural path model by incorporating two predictors (perceived suitability for entertainment news and political feature news), three mediators (information seeking, social utility, and accessibility), and two behavioral outcomes (concentration ratio of smart phone news use and amount of social media news with other mobile news) into the model. Two predictor variables and two covariates were used in the analysis as exogenous variables, and three intervening variables and two outcome variables were used as endogenous variables. The disturbances of two predictors, three mediators, and two outcome variables were allowed to correlate with one another (see Figure 1 for a visual summary). To control for the effects of demographic characteristics, gender, age, and education were included in the path model as exogenous variables, from which pathways were drawn to all the endogenous variables.

To assess the overall model fit, the root mean square error of approximation (RMSEA), the standardized root mean square residual (SRMR), and the comparative fit index (CFI) were used as the primary fit indices. For both RMSEA and SRMR, the smaller value, the better the fit. Following the convention (Boomsma, 2000; Kline, 2005), we considered an RMSEA $\leq .05$ to be 
a close approximation, an RMSEA of between .05 and .08 as reasonable, and an SRMR $<.08$ as favorable. As for CFI, we considered a value of .95 or above as satisfactory and a value of .90 or above as acceptable (Kline, 2005).

\section{Results}

\subsection{Testing the Hypothesized Model}

A structural equation modeling analysis using the ML estimator was implemented to test the hypothesized path model. The SEM model did not provide a sufficiently good fit to the data: $\chi^{2}(10)=40.43, p<.001 ;$ RMSEA $=.104(90 \%$ confidence interval $=.072-.0139) ;$ SRMR $=.050 ; \mathrm{CFI}=.902$. However, the model fit became satisfactory level when non-significant pathways were removed: $\chi^{2}(16)=44.88, p<.001$; RMSEA $=.080(90 \%$ confidence interval $=.053-.0108) ; \mathrm{SRMR}=.052 ; \mathrm{CFI}=.907$. Each time an insignificant path was excluded from the model, the analysis was repeated on the modified model. As a result, only significant pathways were retained in the final path model. As noted earlier, all the parameters were estimated twice, once using ML estimation and once using the bootstrap method. With the 95\% bias-corrected confidence intervals (CI) for all values of interest, we found that none of our results, given in the next section, changed in terms of statistical significance when assessed with the bootstrap method. Figure 2 depicts the final model that we obtained.

\subsection{Summary of Findings}

\subsubsection{Test of Hypotheses}

First, H1 posited users' perceived suitability of accessing two types of news on a mobile device associated with three motivations for mobile news usage. Consistent with our hypothesis, 
the path analysis revealed significant relationships between smart phone news perceptions and motivations for news use with smart phones. Two predictors, perceived suitability for entertainment news (EN) and political feature news (PN) were significantly associated with all three intervening variables, information seeking (IS), social utility (SI), and accessibility (AC) one another (for EN $\rightarrow$ IS, unst. $\beta=0.148, S E=.054, p<.01$; for PN $\rightarrow$ IS, unst. $\beta=0.365, S E$ $=.046, p<.001$; for $\mathrm{EN} \rightarrow \mathrm{SU}$, unst. $\beta=0.245, S E=.062, p<.001$; for $\mathrm{PN} \rightarrow \mathrm{SU}$, unst. $\beta=$ $0.215, \mathrm{SE}=.053, p<.001$; for $\mathrm{EN} \rightarrow \mathrm{AC}$, unst. $\beta=0.275, \mathrm{SE}=.056, p<.001$; for $\mathrm{PN} \rightarrow \mathrm{AC}$, unst. $\beta=0.125, S E=.048, p<.01)$. Hence, $\mathrm{H} 1$ was supported.

Second, as for $\mathrm{H} 2$ hypothesized mobile news consumption behaviors would differ as a function of different motivations. As we expected, we found two of the three mediators, information seeking (IS) and accessibility (AC) were significantly related to two outcome variables, mobile news use (MN) and social news use (SN), meanwhile no association between was found . More specifically, information seeking had a positive association with both mobile news use and social news use, whereas accessibility had a positive relationship with only mobile news use (for IS $\rightarrow \mathrm{MN}$, unst. $\beta=0.029, S E=.012, p<.05$; for $\mathrm{AC} \rightarrow \mathrm{MN}$, unst. $\beta=0.024, S E$ $=.012, p<.05$; for IS $\rightarrow \mathrm{SN}$, unst. $\beta=3.690, S E=1.105, p<.01)$. Therefore, H2 was also supported.

Last, as noted above, the control variables were introduced in the model. The results indicated that gender was significantly associated with the intervening variables. In addition, education was significantly positively related to social news use. All the predictors and intervening variables accounted for $9.5 \%$ of the variance in mobile news use and for $8.6 \%$ of the variance in social news use. Table 1 presents the unstandardized estimates of the parameters and their standard errors. 


\subsubsection{Tests of indirect effect}

To test the mediation of motivations for news use with smart phones, we used 5,000 bootstrap resamples to compute the indirect effects of perceptions on smart phone news use through motivations for such use. The bootstrap test indicated that perceived suitability for entertainment news (EN) and political feature news (PN) indirectly affected mobile news use (MN) via both information seeking (IS) and accessibility. The bootstrapped bias-corrected CIs for the indirect effects on mobile news use via the information-seeking motivation were (EN $\rightarrow$ IS $\rightarrow \mathrm{MN})=0.001-0.010 ;(\mathrm{PN} \rightarrow$ IS $\rightarrow \mathrm{MN})=0.003-0.019$. For the effects via the accessibility motivation, they were $(\mathrm{EN} \rightarrow \mathrm{AC} \rightarrow \mathrm{MN})=0.001-0.013 ;(\mathrm{PN} \rightarrow \mathrm{AC} \rightarrow \mathrm{MN})=$ $0.001-0.007$. The analysis also showed that two predictors indirectly influenced social news use (SN) via the information-seeking motivation. The bootstrapped bias-corrected CIs for the indirect effects on social news use via information seeking were $(\mathrm{EN} \rightarrow \mathrm{IS} \rightarrow \mathrm{SN})=0.172$ $1.157 ;(\mathrm{PN} \rightarrow \mathrm{IS} \rightarrow \mathrm{SN})=0.542-2.288$

\section{Discussion}

The purpose of this study was threefold: (1) to investigate the relationship between users perceptions of the suitability of using a smartphone to access two types of mobile news political feature news and entertainment news, (2) to determine users' reading motivations for mobile news via a smart phone — information seeking, social utility, or accessibility, and (3) to explore how this relationship is associated with behaviors relating to both smart phone news use and social media news use.

Our analysis found significant associations between users' perceived suitability of two types of news with all three reading motivations for mobile news; however, contrary to our 
expectation, users' perceptions of the suitability of different types of news had the same effect on all three motivations for using mobile news. In other words, users' perception of the suitability of political feature news and entertainment news generated the same types of motivations. These results imply that, though the entertainment news is the most prevalent news type in mobile news app and social networking sties (de Zuniga et al., 2012; Horan, 2012; Pew Research Center, 2012), mobile users are likely to perceive political feature news as much suitable for consuming with mobile devices as entertainment news. This can be interpreted in two ways. First, it is possible that people hold off on making a decision about the suitability of types of news delivered through a mobile device in that the consumption of mobile news are not perfectly penetrated to news readers; alternatively, the perception about the suitability of news types on a mobile device might have not been fully created among smartphone users even though the content targeted in mobile devices differs tremendously from that of traditional media channels due to the exclusive characteristics of mobile devices (e.g., low bandwidths of wireless network, small screen size, reduced CPU, data storage limitation) (Timmins et al., 2006). In any case, we believe that if mobile devices become more popular as a news source, it is expected to show different results.

In addition, the finding shows that information seeking influenced both mobile news apps use and social media news use on mobile phones, while the social utility motive is not a significant predictor of the use of these two types of mobile news sources. That is, even though mobile media, especially smart phones, afford users many opportunities to engage in various news-related activities, such as news sharing, news-based-opinion sharing, and other social interactions with news information, these media are not distinct from other media offering news in that all news consumption is basically influenced by the information-seeking motivation. 
Furthermore, the bootstrap tests indicate no indirect effect of social utility on the relationship between perceived suitability of mobile news and the consumption of mobile news either via mobile news apps or social networking sites. It is interesting to note that mobile news consumers are not motivated by social utility even when using social media news. With respect to such an insignificant effect of social utility motivation on social media use, there can be two possible explanations. First, regardless of social media's unique abilities to enable users to connect, interact, and communicate with their friends in social networks (e.g., Correa et al., 2009; Ellison et al., 2007; Ross et al., 2009; Valenzuela et al., 2009), the reason why we got the result that seems opposite to the general notion that sociability is one of the predominant motivations for using social media, is because information seeking is still a primary reason for individuals' social media news consumption, which supports the argument that information seeking is a critical factor affecting users' media consumption (e.g., Shah et al., 2006). Thus, it is possible to posit that mobile news use does not differ in any fundamental way from the use of other forms of news available from the mass media such as newspapers, television, and even the Internet (e.g., Mitchelstein \& Boczkowski, 2010). Another possible explanation is related to diverse types of news consuming behaviors in SNSs. That is, if we measured news consumption behaviors in social networking sites by specifying them with different types of consuming behaviors, given that news consumption behaviors on social networking sites are diversified in that people can share, discuss news in addition to just reading it, then, the results would be different. Therefore, for the future study, we suggest measuring news consumption behaviors in social networking sites with more detailed scales.

Another interesting finding is that accessibility turned out to be a significant indicator for predicting the usage of mobile news apps or websites. It indicates that accessibility is still an 
important reason underlying the consumption of mobile news. Furthermore, the indirect effect test shows that accessibility motivation is a significant mediator between perceived suitability of both types of mobile news and the consumption of mobile news apps. However, it did not mediate the association between perceived suitability for mobile news and the consumption of social media news via smart phones. This difference implies that social news users with smart phones are not likely to consider accessibility in obtaining news information from social media. These results make sense in that news on social networking sites is predominantly delivered through user's sharing behaviors. Therefore, news would not be posted on social networking sites in real time. On the other hand, news in mobile news apps or websites that are operated by news organizations must be updated in real time, therefore users who use such apps or website might have an expectation of real-time uploads and such benefit can be achieved through mobile devices' accessibility.

In addition, those who perceive smart phones as suitable way to obtain political feature news are likely to have a strong information-seeking motive. This motive in turn influences mobile news consumption, from which we can infer that mobile technology offers the potential to engage in political issues. When considering that mobile technology provides opportunities for users to make their social networks for sharing information and opinions in a flexible manner, which enable users to easily access the relevant information, and to participate in expressing his or her opinion, it is expected that news consumption through mobile technology enhances digital agora, in turn, contributes to invigorate the digital public sphere. However, despite the higher expectations regarding the potential of participatory mobile media, empirical evidences given about whether participatory media actually vitalize our digital public sphere are still questionable (see, e.g., Feezell et al.,2009 for digital optimism; Byrne, 2007 for pessimist's view). It is related 
to our presupposition that the overflows of the entertainment news could impede mobile news readers to perceive more serious information as less interesting information for accessing with mobile devices, which in turn weaken mobile users' engagement in various social and political affairs. Though our analyses showed that mobile users' news consumption is still habitual in somewhat aspects, we do not necessarily negate the possibility of civic engagement that mobile technology offers, when considering our findings indicated that the mobile news consumers think upon the political featured news as an important news type as soft news, and mobile news readers accessed the political news via social media platform. Moreover, the finding that mobile news consumers utilized social media news for accessing both types of news motivated by information-seeking provided further implications such that the flexible news consumption helps mobile news consumers to make intricate ways of public opinion and agenda-setting by reconceiving and recasting the news they consumed as agenda setters as well as observers, which calls for situating the mobile news consumption in multiple, interactive communication contexts (Walther et al., 2010).

In sum, based on a structural equation modeling approach, the present study examined psychological and behavioral factors that affect the consumption of mobile-based news. Our results support most of our research hypotheses and suggest that the information-seeking motivation is the key factor influencing the consumption of mobile news. In spite of several notable findings, however, this study also has some limitations. First, we did not fully account for the social utility motivation, because social utility is factorized as a single dimension, such that the social utility motive might be compounded with the other motives. In order to consider why an association between the social utility motivation and mobile news use was not found, it is necessary to include the interpersonal utility and entertainment motives. Therefore, we suggest 
that future studies consider other motivational dimensions in order to clarify the effect of some specific motivations on mobile news consumption. In addition, the current study only considered one primary example of hard and soft news, respectively, but if we can take other types of hard and soft news into consideration when measuring people's suitability perception for using mobile news consumption, then we could find more interesting results. 
Table A.1

Robust Maximum Likelihood Parameter Estimates

\begin{tabular}{llllllll}
\hline Parameter & Unst. & $S E$ & St. & Parameter & Unst. & $S E$ & St.
\end{tabular}

Effects of Perceptions on Smart Phone News Use, Motivations for News Use with Smart Phone, and Socio-Demographic Characteristics

\begin{tabular}{|c|c|c|c|c|c|c|c|}
\hline $\mathrm{PN} \rightarrow \mathrm{IS}$ & $0.36^{* * *}$ & .05 & .42 & $\mathrm{IS} \rightarrow \mathrm{SN}$ & $3.27^{*}$ & 1.34 & .17 \\
\hline $\mathrm{EN} \rightarrow \mathrm{IS}$ & $0.15^{* *}$ & .05 & .15 & Female $\rightarrow$ IS & $-0.16^{* *}$ & .06 & -.14 \\
\hline $\mathrm{PN} \rightarrow \mathrm{SU}$ & $0.21 * * *$ & .05 & .23 & Age $\rightarrow$ IS & $0.04^{*}$ & .02 & .15 \\
\hline $\mathrm{EN} \rightarrow \mathrm{SU}$ & $0.25 * * *$ & .06 & .23 & Female $\rightarrow$ SU & $-0.20 * *$ & .07 & -.16 \\
\hline $\mathrm{PN} \rightarrow \mathrm{AC}$ & $0.13 * *$ & .05 & .16 & Female $\rightarrow$ AC & $-0.13^{*}$ & .07 & -.11 \\
\hline $\mathrm{EN} \rightarrow \mathrm{AC}$ & $0.27 * * *$ & .06 & .27 & Age $\rightarrow \mathrm{MN}$ & $-0.12 * * *$ & .00 & -.26 \\
\hline $\mathrm{IS} \rightarrow \mathrm{MN}$ & $0.03 *$ & .01 & .15 & Education $\rightarrow \mathrm{SN}$ & $1.61^{* *}$ & .50 & .21 \\
\hline $\mathrm{AC} \rightarrow \mathrm{MN}$ & $0.02 *$ & .01 & .12 & & & & \\
\hline
\end{tabular}

Note. Unst. $=$ Unstandardized Estimate, $S E=$ Standard Error, St. $=$ Standardized Estimate, $\mathrm{PN}=$ Perceived Suitability of Political feature news, EN = Perceived Suitability of Entertainment News, IS = Information Seeking, SU = Social Utility, AC = Accessibility, MN = Mobile News Use, $\mathrm{SN}=$ Social Media News Use. Gender is a dummy-coded variables (female vs. male).

${ }^{*} p<.05 ; * * p<.01 ; * * * p<.001$ 


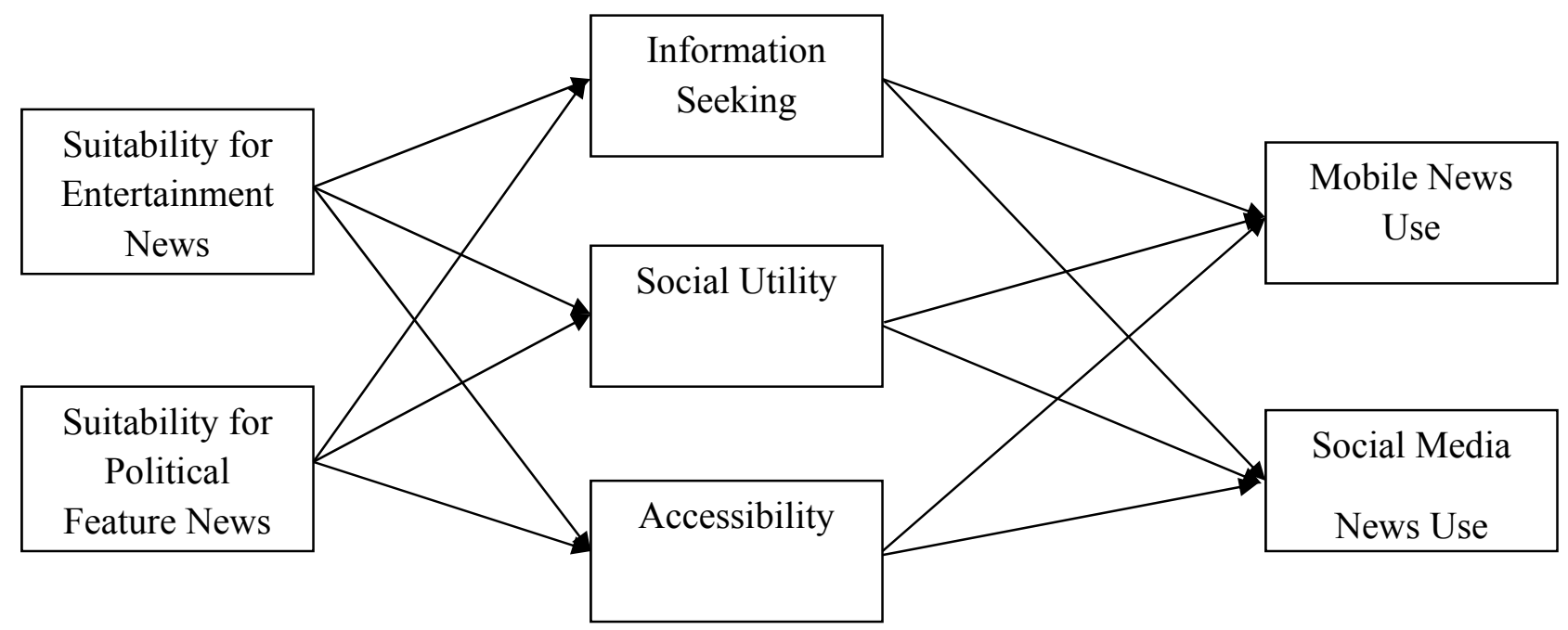

Fig. A.1 Model Suggestion 


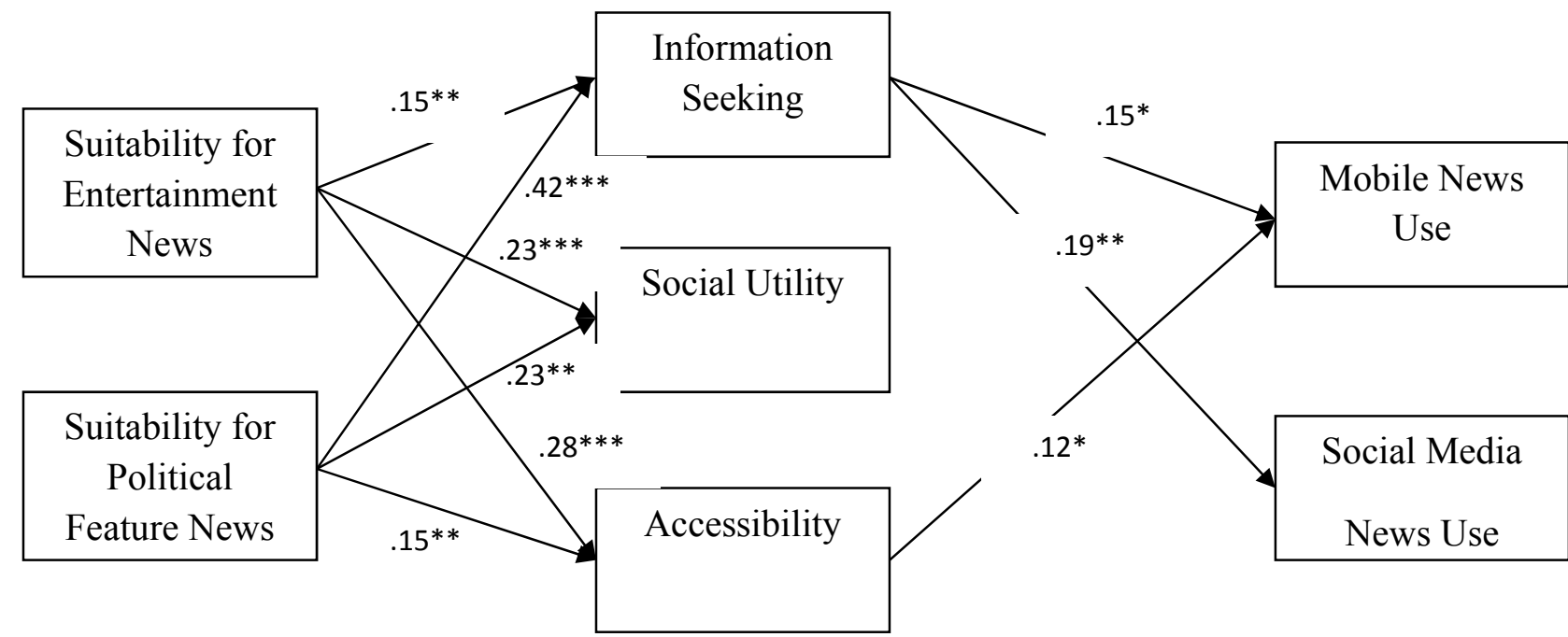

$$
\begin{array}{r}
X^{2}(10)=44.88 \\
\text { CFI }=0.91 \\
\text { SRMR }=0.05 \\
\text { RMSEA }=0.08(90 \% \text { CI }=.053-.108)
\end{array}
$$

Note. All estimates are standardized regression weights. Effects of gender, age, and education are statistically controlled but they are not shown in the figure for reasons of clarity. Inter-factor correlations are not shown for the same reason.

${ }^{*} p<.05 ; * * p<.01 ; * * * p<.001$ 


\section{References}

Baron, R.M., Kenny, D.A. 1986. The moderator-mediator variable distinction in social psychological research: Conceptual, strategic, and statistical considerations. Journal of Personality and Social Psychology 51 (6), 1173-1182.

Blumler, J. 1979. The role of theory in uses and gratifications studies. Communication Research 6, 9-36.

Boomsma, A. 2000. Reporting analyses of covariance structures. Structural Equation Modeling 7, $461-483$.

Boomsma, A., Hoogland, J. J. 2001. The robustness of LISREL modeling revisited. In R. Cudeck, S. du Toit, \& D. Sorbom (Eds.), Structural Equation Modeling Present and Future (pp. 139-168). Chicago, IL: Scientific Software International.

Borgatti, S. P., Cross, R. 2003. A relational view of information seeking and learning in social networks. Management Science 49 (4), 432-445.Byrne, D.N. 2007. Public discourse, community concerns, and civic engagement: Exploring black social networking traditions on BlackPlanet.com. Journal of Computer-Mediated Communication, 13, 1. Retrieved from http://jcmc.indiana.edu/vol13/issue1/byrne.html (April, 4, 2014)

Choi, H., Choi, Y. J., Kim, K. M. 2011. The understanding of building trust model on smartphone application: Focus on users' motivation modeling. In K. J. Kim, \& S. J. Ahn (Eds.), Proceedings of the International Conference on IT Convergence and Security 2011 (pp. 13-20). NY: Springer Science Business Media.

Conway, J. C., Rubin, A. M. 1991. Psychological predictors of television viewing motivation. Communication Research 18 (4), 443-463.

Correa, T., Hinsley, A. W., de Zúñiga, H. 2009. Who interacts on the Web? The intersection of users' personality and social media use. Computers in Human Behavior 26, 247-253.

Cross, R., Sproull, L. 2004. More than an answer: Information relationships for actionable knowledge. Organization Science 15 (4), 446-462.

Efron, B., Tibshirani, R. J. 1993. An introduction to the bootstrap. Boca Raton, FL: Chapman \& Hall.

Ellison, N. B., Steinfield, C., Lampe, C. 2007. The benefits of Facebook "friends": Social capital and college students' use of online social network sites. Journal of Computer-Mediated Communication 12 (4), 1143-1168. 
Falaki, H., Mahajan, R., Kandula, S., Lymberopoulos, D., Govindan, R., Estrin, D. 2010. Diversity in smartphone usage. Proceedings of the International Conference Mobile Systems, Applications and Services, In MobiSys. Feezell, J., Conory, J., Guerrero, M. 2009. Facebook is ... Fostering Political Engagement: A Study of Online Social Networking Groups and Offline Participation. Paper presented at the American Political Science Association meeting in Toronto, Canada.

Ferguson, D. A., Perse, E. M. 2000. The World Wide Web as a functional alternative to television. Journal of Broadcasting \& Electronic Media, 44, 155-174.

Flavián, C., Guerra, R. 2006. The role of readers' motivations in the choice of digital versus traditional newspapers. Journal of Targeting, Measurement and Analysis of Marketing 14 (4), 325-335.

Hirschman, E., Holbrook, M. 1982. Hedonic consumption: Emerging concepts, methods and propositions. Journal of Marketing 46 (3), 92-101.

Holbrook, M. 1994. The nature of customer value: An axiology of services in the consumption experience. In R. T. Rust et al. (Eds.), Service quality: New directions in theory and practice (pp. 21-71). CA: Sage publications.

Kang, H., Lee, J.K., You, K. H., Lee, S. 2013. Does online news reading and sharing shape perceptions of the Internet as a place for public deliberation? Mass Communication and Society $16(4), 533-556$.

King, W. R. He, J. 2006. A meta-analysis of the technology acceptance model. Information and Management 43 (6), 740-755.

Kiousis, S., Dimitrova, D. V. 2006. Differential impact of Web site content: Exploring the influence of source (public relations versus news), modality, and participation on college students' perceptions. Public Relations Review 32, 177-179.

Kline, R. B. 2005. Principles and practices of structural equation modeling (2nd ed.). New York, NY: Guilford Press.

Ko, H., Cho, C.-H., Roberts, M. S. 2005. Internet uses and gratifications: A structural equation model of interactive advertising. Journal of Advertising 34 (2), 57-70.Ladhani, N. 2010. Making a difference: 140 characters at a time. Social Policy Magazine, 43. Retrieved from Academic Search Premier Database.

Leung, L., Wei, R. 2000. More than just talk on the move: A use and gratification study of the cellular phone. Journalism and Mass Communication Quarterly 77 (2), 308-320. 
Levy, M. R., Windahl, S. 1984. Audience activity and gratifications: A conceptual clarification and exploration. Communication Research 11, 51-78.

Mendelsohn, H. 1964. Listening to radio. In L.A. Dexter \& D.M. White (eds), People, Society and Mass Communication, pp. 239-48. New York: Free Press.

MacKinnon, D. P., Fairchild, A. J., Fritz, M. S. 2007. Mediation analysis. Annual Review of Psychology 58, 593-614.

Metzger, M. J., Flanagin, A. J. 2002. Audience orientations toward new media. Communication Research Reports 19, 338-351.

Mitchelstein, E., Boczkowski, P. 2010. Online news consumption research: An assessment of past work and an agenda for the future. New Media \& Society 12 (7), 1085-1102.

Muthen, L. K., Muthen, B. O. 2007. Mplus users' guide. Los Angeles, CA: Muthen \& Muthen.

Papacharissi, Z., Rubin, A. M. 2000. Predictors of Internet usage. Journal of Broadcasting and Electronic Media 44, 175-196.

Palmgreen, P., Wenner, L. A., Rayburn, J. D. 1980. Relations between gratifications sought and obtained: A study of TV News. Communication Research 7, 161-192.

Pew Research Center. 2010. Understanding the participatory news consumer: How internet and cell phone users have turned news into a social experience from the World Wide Web. Retrieved from http://www.pewinternet.org.

Pew Research Center. 2012. The State of the News Media 2012: An Annual Report on American Journalism. Retrieved from http://stateofthemedia.org/2012/mobile-devicesand-newsconsumption-some-good-signs-for-journalism/?src = prc-number\#fn-11552-2.

Preacher, K.J., Hayes, A.D. 2004. SPSS and SAS procedures for estimating indirect effects in simple mediation models. Behavior Research Methods, Instruments, \& Computers 36 (4), 717-731.

Preacher, K. J., Hayes, A. F. 2008. Contemporary approach to assessing mediation in communication research. In A. F. Hayes, M. D. Slater, L. B. Snyder (Eds.), The Sage source book of advanced data analysis methods for communication research (pp. 13-54). Thousand Oaks, CA: Sage.

Ross, C., Orr, E. S., Sisic, M., Arseneault, J. M., Simmering, M. G., Orr, R. R. 2009. Personality and motivations associated with Facebook use. Computers in Human Behavior 25 (2), 578 586. 
Rubin, A. M. 2002. The uses-and-gratifications perspective of mass media effects. In J. Bryant \& D. Zillmann (Eds.), Media effects: Advances in theory and research (pp. 525-548). Mahwah, NJ: Lawrence Erlbaum.

Rubin, A. M. 2009. The uses-and-gratifications perspective on media effects. In J. Bryant \& M. B. Oliver (Eds.), Media effects: Advances in theory and research (pp. 165-184). New York, NY: Routledge.

Scott, D.K., Gobets, R.H. 1992. Hard news/soft news content of the national broadcast networks, 1972-1987. Journalism Quarterly 69 (2), 406-412.

Shah, D. V., Scheufele, D. A. 2006. Explicating opinion leadership: Nonpolitical dispositions, information consumption, and civic participation. Political Communication 23, 1-22.

Sheth, J., Newman, B., Gross, B. 1991. Consumption values and market choices, theory and applications. OH: South-Western Publishing.

Sharma, C. US wireless data market update - Q3 2009. Retrieved from http://www.chetansharma.com/usmarketupdateq309.htm.

Steers, R. M., Porter, L. W. 1991. Motivation and work behavior (5th ed.). New York, NY: McGraw-Hill.

Swanson, D. 1987. Gratification seeking, media exposure, and audience interpretations: Some directions for research. Journal of Broadcasting and Electronic Media 31, 237-254.

Valenzuela, S., Park, N., Kee, K. F. 2009. Is there social capital in a social network site? Facebook use, and college students' life satisfaction, trust, and participation. Journal of Computer-Mediated Communication 14 (4), 875-901.

Verkasalo, H. Lopez-Nicolas, C., Molina-Castillo, F. J., Bouwman, H. 2010. Analysis of users and non-users of smartphone applications, Telematics and Informatics, 27, 242255.Walther, J.B., DeAndrea, D., Kim, J., Anthony, J.C. 2010. The influence of online comments on perceptions of antimarijuana public service announcement on Youtube. Human Communication Research, 36 (4), 469-492.

Westlund, O. 2008. From mobile phone to mobile device: News consumption on the go. Canadian Journal of Communication 33, 443-463.

Westlund, O., Bohlin, E. 2008. Mobile Internet adoption and use: Results from a national survey in Sweden. Paper presented at the $17^{\text {th }}$ Biennial ITS Conference, Montreal, QC.

Wicklund, R. A., Gollwitzer, P. M. 1982. Symbolic self-completion. Hillsdale, NJ: Lawrence Erlbaum. 
Yuan, Y.C., Fulk, J., Monge, P. R., Contractor, N. 2010. Expertise directory development, shared task-interdependence, and strength of communication network ties as multilevel predictors of expertise exchange in transactive memory work groups. Communication Research 37 (1), $20-47$.

You, K. H., Lee, S., Lee, J.K., Kang, H. 2013. Why read online news? The structural relationships among motivations, behaviors, and consumption in South Korea. Information, Communication \& Society 16 (10), 1574-1595.

Zeithaml, V. 1988. Consumer perceptions of price, quality, and value: A means-end model and synthesis of evidence. Journal of Marketing 52 (3), 2-22. 